\title{
La muerte del filósofo
}

\author{
Francisco Lafarga \\ Universidad de Barcelona
}

Resumen

Se analiza, en una primera parte del artículo, la imagen de la atormentada muerte del filósofo como ejemplo negativo, insistiendo en la presentación que de la muerte de Voltaire se hace en varios textos del siglo XVIII, mientras que en la segunda parte se insiste en la imagen de la muerte «filosófica»o aspecto positivo de la misma, como muerte serena y tranquila.

La imagen de la muerte está muy presente en la literatura del siglo xvIII, y en muchas ocasiones de manera muy «tradicional», utilizando elementos antiguos, que se hallan en las danzas de la muerte medievales.

Una simple ojeada a la bibliografía de Aguilar Piñal ${ }^{1}$ nos proporcionaría noticia de multitud de textos específicos que tienen a la muerte por protagonista. La mayoría, por supuesto, son sermones o discursos fúnebres, libros de preparación a la buena muerte y, en general, textos de eclesiásticos. Aunque también alguna obra que pretende tener características literarias, como las de LouisAntoine Caraccioli, muchas de las cuales fueron traducidas, como sabemos, por el infatigable F. M. Nifo, y en especial la Pintura de la muerte, de 1783.

Además de las evocaciones del infierno o del juicio final, otras escenas y otros temas de reflexión presentan a los espíritus la terrible y temible imagen \footnotetext{
vols.

${ }^{1}$ Francisco Agullar Piñal, Bibliografía de autores españoles del siglo xVIII, Madrid, CSIC, 1981-1999, 9
}

Cuadernos de Estudios del Siglo XVIII, núms. 10-11. Oviedo, Instituto Feijoo de Estudios del Siglo XVIII, Universidad de Oviedo, 2002 , págs. 63-74. 
de la muerte. En especial el propio acto de morir, como acto último, que puede decidir toda una vida y llevar al hombre a su salvación o a su condenación.

\section{El «filósofo» en su muerte}

En este contexto, la muerte atormentada del pecador, del malvado, del impío o del ateo se presta a descripciones ricas en detalles y supuestamente edificantes para el público.

En el siglo XVIII, el «filósofo» reúne, para las mentalidades tradicionales, todas esas cualidades, unidas a otras características — fruto de su espíritu crítico- que lo hacen aparecer casi como la personificación del demonio.

Efectivamente, asistimos en muchos textos de la llamada «literatura antifilosófica» a una verdadera demonización de la figura del nuevo pensador, atribuyéndole, claro está, rasgos que en muchos casos no tuvo, o generalizando características que sólo algunos de ellos poseían: pienso, sobre todo, en el sambenito del ateísmo, colgado a todos los filósofos, cuando, como sabemos, la mayoría eran partidarios del deísmo y totalmente contrarios al ateísmo.

En el ámbito español, la figura del philosophe más relevante, podríamos decir, el filósofo por antonomasia, es Voltaire, en quien parecen converger las iras de los apologistas de la religión católica y los defensores de la tradición en la política, la moral y la ideología. ${ }^{2}$

Esta actitud, a la que voy a referirme luego con detenimiento, contrasta con la neutralidad y la asepsia de la nota necrológica, tal y como aparece en la prensa de la época. Así, puede leerse en la Gaceta de Madrid del 23 de junio de 1778: «A 30 del pasado falleció en esta capital [París] de 84 años y algunos meses Francisco María Arouet de Voltaire, gentilhombre ordinario del rey y uno de los 40 de la Academia francesa» (nº 25, pág. 244).

Poco tiempo después se publicó — algo más amplia— la gacetilla correspondiente a la defunción de Rousseau:

El 2 del corriente [julio] murió de 72 años en Ermenonville distante de aquí [París] 10 leguas y cercano a Montmorency, en casa del marqués Girardin, Juan Jacobo Rousseau, ciudadano de Ginebra, harto conocido por sus paradojas. Se había retirado allí tres semanas con ánimo de pasar parte del verano herborizando, a cuyo ejercicio tenía mucha afición (Gaceta de 4 de agosto de 1778, nº 31, pág. 309).

${ }^{2}$ Para una ampliación de todo esto puede verse mi Voltaire en España, Barcelona, Universidad de Barcelona, 1982 (versión revisada en Voltaire en Espagne, Oxford, Voltaire Foundation, 1989). 
Pero los textos que voy a comentar aquí tienen un tono muy distinto. El primero de ellos es un librillo titulado El éxito de la muerte correspondiente a la vida de los tres supuestos héroes del siglo XVIII, Voltaire, D'Alembert y Diderot, publicado en Madrid en $1792^{3}$. Se dice traducido del francés al italiano, y de esta lengua al castellano por José Domenichini ${ }^{4}$. Aunque he localizado y consultado la versión italiana (L'esito della morte corrispondente alla vita dei tre suposti eroi del secolo decimottavo Voltaire, Alembert e Diderot, Asís, 1790), que se encuentra en la B. de la Universidad de Barcelona, no he dado con el original francés.

A pesar del título, de las 291 páginas de que consta la obra, 264 están relacionadas con Voltaire, y consisten en el relato de su regreso a París en febrero de 1778, de los homenajes que se le tributaron, de su enfermedad, agonía y muerte, de las peripecias de su entierro, de las infructuosas gestiones de d'Alembert para que se le hiciera una misa de funeral como académico, y de las honras fúnebres que se le tributaron en la logia masónica de las Nueve Hermanas. El relato propiamente dicho está cortado por la reproducción de cartas, declaraciones y otros textos relativos a los acontecimientos, así como por dos breves paréntesis sobre la muerte de otros dos filósofos: el inglés Bolingbroke y la antigua amante de Voltaire Mme du Châtelet («dama filósofa»).

También relacionados con Voltaire se encuentran otros dos textos: un exhorto del obispo de Amiens sobre las obras del filósofo y una descripción del castillo de Ferney, interesante porque da los pormenores de los ornamentos conmemorativos que se añadieron tras la muerte de Voltaire, cuando la finca pasó a su nuevo dueño, el marqués de Villette.

Comparadas con el espacio concedido a Voltaire, resultan casi despreciables las páginas consagradas a los otros dos «héroes»: la muerte de D’Alembert ocupa apenas 20 páginas, mientras que la de Diderot se despacha en poco más de cinco.

El complicado proceso de la muerte de Voltaire tiene, en el relato - aunque también en la realidad - tres fases netamente diferenciadas: la preparación para la muerte, el óbito propiamente dicho y las ceremonias posteriores, entierro y funerales. Y planea sobre el conjunto un conflicto de competencias en materia de administración de sacramentos y de inhumación, adjudicadas a

\footnotetext{
${ }^{3}$ El título completo es: El éxito de la muerte correspondienbte a la vida de los tres supuestos héroes del siglo XVIII, Voltaire, D'Alambert y Diderot, demostrado con la simple y verdadera narración de su muerte. Añadido un exhorto del Ilmo. Señor Obispo de Amiens sobre la colección de las obras de Voltaire, y una descripción de Ferney. Traducido del idioma francés al italiano, y de éste al castellano por don Joseph Domenichini, quien lo dedica al Excmo. Señor marqués de Branciforte, Madrid, Imprenta de Joseph Doblado, 1792.

${ }^{4}$ De este autor Aguilar Piñal menciona, además, la traducción de una Historia de José Balsamo, supuesto conde de Cagliostro, que no obtuvo licencia para la impresión (Bibliografía, III, $\mathrm{n}^{\circ}$ 699).
} 
los párrocos de la demarcación donde residía el enfermo, en este caso, el párroco de San Sulpicio en París.

Voltaire, que durante años había expresado su pánico ante la eventualidad de ser arrojado a un vertedero, como ocurría con los que morían sin recibir la extremaunción y, en el caso de pecadores públicos y conocidos, sin hacer retractación formal de sus faltas, pensó en acercarse a la religión y aceptó redactar una retractación y aun confesarse, aunque no con el cura que le correspondía, sino con otro confesor menos riguroso que él. Rechazó la fórmula de retractación que se le había presentado e hizo redactar otra menos comprometedora, en la que decía, entre otras cosas, que «muero en la religión católica, en la que nací, esperando en la divina misericordia que se dignará perdonarme todos mis yerros, y que si acaso hubiese escandalizado a la Iglesia pido perdón a ella y a Dios». De hecho esta retractación pareció insuficiente tanto al párroco como al arzobispo de París, los cuales redoblaron sus esfuerzos para lograr otra más contundente y que el enfermo recibiera los sacramentos, sin lograrlo. Todo esto sucedió entre finales de febrero y principios de mayo, momento en que su salud se quebrantó definitivamente. Parece que el excesivo café que tomaba como estimulante, y que finalmente le produjo insomnio, mezclado con el opio que le aconsejó uno de sus amigos, le hicieron caer en una postración de la que no había de recuperarse.

El relator cuenta con detalle los últimos días del filósofo, insistiendo al empezar que conservó sus sentidos hasta el final, de tal modo que su falta de arrepentimiento debía verse como algo consciente y voluntario, y no fruto del delirio o la inconsciencia. Con todo, los terribles dolores que padecía, debidos a una infección en los riñones y a la retención de orina, le hacían enfurecerse sobremanera:

En medio de tanto padecer, el desgraciado Voltaire no fue filósofo ni cristiano, antes, por el contrario, se mostró aun menos que hombre, pues que no supo sufrir a ninguno de los que le asistían, ni fue tampoco capaz de sufrirse a sí mismo. Muy a menudo se enfurecía y desesperaba, de modo que es imposible explicarlo; gritaba a cada instante, exclamando: «¡Ay de mí! Que me quemo, echadme en un baño helado». Blasfemaba, amenazaba, vomitaba las mayores injurias, particularmente contra los que le asistían, y los castigaba cuando se le acercaban (págs. 76-77).

Llegados los sacerdotes y habiéndole hecho a Voltaire todas las recomendaciones posibles para que se retractase y pidiese confesión, éste rechazó con obstinación y furor los sacramentos; y así, desasistido, murió entre terribles dolores: 
Poco antes de expirar tuvo grandes convulsiones, haciendo tales gestos que atemorizaron a los circunstantes. La enfermera Roger, sin embargo de estar acostumbrada a ver y a asistir moribundos, poco le faltó para morir de espanto, y confiesa que estuvo muchísimo tiempo después sin poder borrar de su fantasía la horrible imagen de Voltaire moribundo. Madama Bardi, mujer del cocinero de Voltaire, quien le asistió en los últimos cuatro días de su enfermedad, fue tan penetrada del temor viendo los ademanes, las bascas y la desesperación de su amo en aquellos extremos, que cayó gravemente enferma (págs. 104-105).

El caso del entierro de Voltaire no fue menos rocambolesco. Como no se había obtenido permiso para que lo enterraran en su parroquia, y ante la posibilidad de ser arrojado a la fosa común por inconfeso y recalcitrante, sus parientes decidieron sacar el cadáver de París y llevarlo a la abadía de Seillières, cerca de Troyes, de la que un sobrino de Voltaire, el abate Mignot (que era subdiácono), era abad comanditario, aunque para tal operación convenía hacer pasar a Voltaire todavía por vivo. Una vez realizada la autopsia, fajaron el cadáver, lo vistieron convenientemente y lo sentaron en su carroza, así pudo salir por las puertas de París sin problema alguno, ser llevado a la abadía y enterrado con discreción en su iglesia. Allí permaneció su cuerpo hasta 1791, en que fue llevado en triunfo a París y colocado con todos los honores en la iglesia de Santa Genoveva, rebautizada como Panteón.

A pesar del carácter sesgado de la obra que estoy comentando, pues podríamos pensar que es tendenciosa y desea dar una imagen terrible y, por ello, edificante, de la muerte del filósofo por antonomasia, lo cierto es que sus contenidos coinciden grosso modo con la versión de los biógrafos de Voltaire ${ }^{5}$. Es cierto que algunos elementos aparecen algo exagerados, que se han ocultado algunos detalles (en especial el texto manuscrito que dejó y que se conserva, en el que puede leerse: "Je meurs en adorant Dieu, en aimant mes amis, en ne haïssant pas mes ennemis, en détestant la superstition»), pero el conjunto no resulta muy alejado de la realidad, a excepción de ciertos comentarios o calificativos dirigidos a Voltaire, del tipo: «jefe de los incrédulos», «viejo orgulloso», «fingido héroe», «energúmeno», etc.

En cuanto a otros relatos sobre la muerte de Voltaire publicados en España, conviene citar en primer lugar un resumen de la parte correspondiente al patriarca de Ferney contenida en la obra anterior, que apareció en 1793 en Cádiz con el título Retrato histórico de la horrible muerte de aquel monstruo de la iniquidad M. Voltaire, cuyas perversas doctrinas pueden haber tenido mucha parte en los

${ }^{5}$ Puede verse, entre otros, Jean Orieux, Voltaire ou la royauté de l'esprit, París, Flammarion, 1966. 
desórdenes que afligen a la Francia y que tantas lágrimas cuestan a la Europa: sacado para desengaño de sus perversos sectarios. Este opúsculo fue reproducido en el Diario de Valencia del 14, 15, 16 y 23 de junio del mismo año ${ }^{6}$. Por su parte, en la Novísima recopilación (ley VIII, título xVIII, nota 9) se menciona un Extracto de la muerte de Mr. de Voltaire, recordando la prohibición de publicar obras relacionadas con Francia de 17 de junio de 1793. No he podido consultar una Colección de las particularidades de la vida y muerte de un pretendido filósofo moderno (Madrid, Villalpando, 1796), traducida del francés y que según Aguilar Piñal ${ }^{7}$, versa así mismo sobre Voltaire.

Aunque algo adentrada en el siglo xIx, pues no se publicó hasta 1829, es interesante la obrita de José María Cagigal, marqués de Casa Cagigal, titulada Corrección fraterna a los falsos filósofos, pues contiene la más amplia referencia publicada en España sobre Voltaire, a excepción de otro libro al que me referiré en seguida, El juicio final de Voltaire del padre Cevallos ${ }^{8}$. Imagina el autor un encuentro entre Pascal y Voltaire hacia el final de la vida del filósofo. Éste, presintiendo próxima su muerte, quiere arrepentirse de sus errores y pecados, pero su soberbia se lo impide. De nada sirven las prudentes reconvenciones de Pascal, las pruebas que aporta sobre la verdad de la doctrina cristiana y la divinidad de Jesucristo. Al final de la obra, Voltaire muere impenitente.

Antes de comenzar el diálogo entre Pascal y Voltaire, que ocupa la mayor parte del libro, el autor hace una descripción del filósofo, de sus dudas e inquietudes al final de su vida, presentándolo arrepentido de sus obras: «Ya no puedo tardar en descender al sepulcro, y desciendo lleno de tristeza, crímenes y lágrimas, tal vez para verter otras que no acaben jamás» (pág. 9). Y, dirigiéndose a Pascal cuando lo ve llegar: «iApóstol de París... tú te dignas visitar la serpiente Voltaire sin huir de la ponzoña que derrama sobre ti y sobre tus creyentes...!» (pág. 15).

Antes de pasar al gran texto sobre Voltaire, el del P. Cevallos al que antes he aludido, quisiera hacer mención de un papel manuscrito, conservado en el Instituto Feijoo de Estudios del siglo xvIII, titulado Carta de M. de Voltaire a los parisienses, sin fecha, aunque con letra de finales del siglo XVIII, que es la traducción del opúsculo Épître de M. de Voltaire aux Parisiens pour servir de suite à son retour des ombres (París, 1776). El título del opúsculo alude a unos libelos publicados en la misma fecha por Charles-Louis Richard en los que se pre-

\footnotetext{
${ }^{6}$ Según Agullar Piñal, Bibliografía, IX, no 5655.

${ }^{7}$ Agullar Piñal, Bibliografía, IX, no 1051.

${ }^{8}$ Cagigal es también autor de una comedia contra los filósofos, Federico y Voltaire en la quinta de Postdan o Lo que son los sofistas, publicada el mismo año de 1829.
} 
sentaba, antes de tiempo, la muerte de Voltaire, su viaje a los infiernos y su juicio: Voltaire parmi les ombres y Voltaire de retour des ombres et sur le point d'y retourner pour n'en plus revenir. De hecho, no eran los únicos de tal clase: pueden citarse, por ejemplo, el de N.-J. Senlis Relation de la maladie, de la confession et de la fin de M. de Voltaire (1761) o el de A.-J. Chaumieux, Voltaire aux Champs-Elysées (1773).

La epístola, traducida en prosa, presenta a Voltaire a punto de morir y haciendo una confesión general, en la que pasa revista a sus obras, señalando sus defectos y flaquezas, y menciona a sus enemigos, a los que satirizó injustamente:

¿Qué mudanza siente el hombre en su última hora! ¡Qué aislado se halla! Placeres, tesoros, grandeza, todo huye de su vista menos los locos errores. Ellos han huido lejos de la mía. Esto es hecho: el velo cae; los ojos levantados a los cielos y el pie en la losa, yo veo en este momento la augusta verdad derramar su más viva claridad alrededor de mí; ella está acompañada de la razón severa; esta razón por mí despreciada tan largo tiempo, más poderosa hoy, truena en el fondo de mi corazón, el remordimiento y la eternidad lo hielan de terror.

Se retracta de todas sus maldades y termina mostrando su arrepentimiento:

En este día abro los ojos a los rayos de la fe, yo me someto al fuego de la ley divina y bañado en lágrimas de un arrepentimiento sincero quiero morir en el seno de nuestra augusta Madre. Adiós, pueblo admirable, ¡qué dichoso seré yo si os dignáis de colmar el más amado de mis votos! Desgarrad la venda, recoged vuestros sufragios, derribad mi estatua y quemad mis obras.

El ya mencionado Juicio final de Voltaire es obra del jerónimo fray Fernando de Cevallos, una de las primeras figuras de la apologética española del siglo XVIII, autor de numerosos escritos, varios de ellos todavía inéditos. Su obra más notable es la monumental Falsa filosofía o el ateísmo, deísmo, materialismo y demás nuevas sectas, convencidas de crimen de Estado contra los soberanos y sus regalías, contra los magistrados y potestades legítimas (1774-1776), enorme tratado, interrumpido en el tomo VI cuando, al parecer, debería tener el doble. Por causas todavía no esclarecidas, se negaron a Cevallos las licencias necesarias para seguir publicando su obra. Según su biógrafo Juan José Bueno, la causa habría que buscarla en la intervención del propio Voltaire a través de sus amigos y seguidores en España; el mencionado biógrafo llega incluso a afirmar que «Voltaire recibía por la posta los libros que daba a luz el P. Cevallos, de quien sin embargo 
nunca habló indecorosamente en público, respetándolo como a su más erudito y formidable enemigo» ${ }^{9}$.

Más interesante que La falsa filosofía, por lo que respecta a Voltaire, y mucho más entretenida resulta la única obra extensa dedicada totalmente al patriarca de Ferney en España: El juicio final de Voltaire, con su historia civil y literaria y el resultado de su filosofía.

La historia de esta obra es algo compleja. Cevallos la compuso, según sus propias palabras, en los cinco meses que siguieron a la muerte de Voltaire, es decir, a partir de junio de 1778, pero una intriga impidió su publicación; recordemos que dos años le habían sido denegadas las licencias para la continuación de su Falsa filosofía. El autor debió intentar la publicación años más tarde, ya que el prólogo está fechado en 1800. Con todo, las censuras más antiguas, reproducidas en la edición, son de 1809 (el autor había fallecido en 1802), y la aprobación final lleva fecha de 1825. Pero el libro no se publicó en aquella época.

Mucho más tarde el manuscrito fue a parar a manos del erudito y periodista León Carbonero y Sol, quien lo publicó en volumen en 1856, es decir, 78 años después de la composición de la obra.

En líneas generales, la obra consiste en el juicio de Voltaire en los infiernos. Este procedimiento no era nuevo en Francia, y ya he citado varios libelos publicados sobre el particular, incluso antes del fallecimiento de Voltaire. Relata la obra el Viajero de Lemnos, el cual embarca en Gibraltar en un navío francés llamado precisamente Voltaire, que va a embarrancar en la isla de Antíparos el 30 de mayo de 1778 (fecha de la muerte de Voltaire). El único superviviente es el Viajero, el cual, explorando unas cuevas de la isla encuentra a la Verdad en forma de mujer; ésta lo conduce hasta la laguna Estigia, donde hallan a Voltaire a punto de ser juzgado por un tribunal compuesto por Sócrates, Epicuro, Cicerón, Virgilio y Lucrecio, mientras que Luciano de Samosata actúa de relator.

La obra se compone de diez libros o capítulos, en los cuales Luciano relata la vida de Voltaire y comenta sus escritos. El último libro contiene la llegada de Voltaire a París, su enfermedad, muerte y entierro, y no difiere en mucho (aunque contiene varios documentos nuevos, así como comentarios aparecidos en varios periódicos), de lo relatado en el ya citado Éxito de la muerte. Por eso, quizá sea más interesante el primero, en el que se halla una descripción de Voltaire en el momento en que comparece ante su tribunal, según la relata el Viajero:

\footnotetext{
${ }^{9}$ Véase Juan José Bueno, Apuntes biográficos del Reverendo Padre Maestro Fray Fernando de Cevallos en F. de Cevallos, La Sidonia Bética, Sevilla, 1864, pp. I-xxv; la cita está en las pp. XvIII-XIX.
} 
Un momento después vi llegar un espectro o fantasma formidable. [...] La cabeza era de una serpiente con orejas, y en ellas respiraba humo, como por las rasgadas narices y por la boca, que tenía armada con dos hileras de colmillos. [...] En la frente tenía dos cuernos de color y textura de hierro, y entre sus arrugas se entreveían impresas con una marca de fuego estas palabras abreviadas: Ecrasez l'Infâme, Destruid al Infame. De buitre le quedaron las corvas garras llenas de sangre y carne repodrida. Desde el vientre hasta las rodillas se cubría de láminas o escamas de lepra, entre las cuales hervía un prurito que le hacía despedazarse. Desde la nuca hasta el fin de un largo rabo, con el que daba vueltas a su cuerpo, estaba armado con una hilera de espinas corvas o de agudas uñas. De las espaldillas le nacían unas aletas de membrana o de costillas y cuero mugriento, que daban un vuelo torpe y trémulo, así como el del dragón (I, págs. 37-38).

\section{La muerte «filosófica»}

La filosofía del siglo xVIII, en nombre de la libertad del pensamiento, de la autonomía del individuo y del derecho a la felicidad, tomó posición, directa o indirectamente, ante el problema de la muerte, rebatiendo las creencias difundidas y sostenidas por la Iglesia en un episodio tan crucial para el hombre.

De hecho, existen muy pocos textos específicos y de cierta envergadura en los que los filósofos se hayan propuesto sistemáticamente arrebatar a la Iglesia su explotación del pensamiento y del sentimiento de la muerte ${ }^{10}$. Tal vez los únicos ejemplos notables haya que buscarlos en las obras del barón d'Holbach, como las Lettres à Eugénie, las Réflexions sur les craintes de la mort y el Système de la nature. Pero aun cuando el siglo XVIII no produjera una obra maestra en la que se presentara la respuesta filosófica al desafío de la muerte, tal respuesta aparece en multitud de textos de manera fragmentaria, multiforme, mediante repetidos cuestionamientos de los temas de la predicación católica sobre las postrimerías o sobre el comportamiento de los propios católicos. Se trataba, en definitiva, de dominar, o de ayudar a dominar, los antiguos terrores sin el socorro de una religión revelada, de entablar la lucha contra el poder de la muerte.

De hecho, este pensamiento tiene sus fuentes en autores de la Antigüedad, paganos, que ofrecían ejemplos de una actitud ante la muerte no «conta-

\footnotetext{
${ }^{10}$ Sobre este asunto, aparte de algunas noticias en John McManners, Death and Enlightenment, OxfordNueva York, Clarendon Press-Oxford University Press, 1981, y en Michel VovelLe, Mourir autrefois: attitudes collectives devant la mort аих хине et хипе siècles, París, Gallimard, 1990, pueden verse varios capítulos en Robert Favre, La mort dans la littérature et la pensée françaises au Siècle des Lumières, Lyon, Presses Universitaires de Lyon, 1978, en particular el cap. V (págs. 161-183): «La philosophie dissipant les ténèbres».
} 
minada» por el cristianismo. Así, el De natura rerum de Lucrecio o el De senectute de Cicerón fueron debidamente explotados por los pensadores modernos en este tema, y proporcionaron argumentos en favor de la eficacia de la razón por sí sola para domesticar a la muerte. Con esta actitud, se incidía de lleno en las bases del cristianismo. Los esfuerzos de los filósofos se dirigen a denunciar la explotación cristiana de la muerte, a proponer remedios sencillamente humanos contra los temores de la muerte y a desterrar en particular las aprensiones suscitadas por una eventual resurrección del alma así como por las presuntas ansias de la agonía.

La muerte «filosófica» se presenta como una muerte dulce, sin angustias, con la tranquilidad que da la virtud y el saberse querido y apreciado por los demás; una muerte digna. Esa muerte filosófica tiene sus precedentes entre los antiguos: Sócrates, Cicerón, Catón, Séneca. Se va constituyendo así una especie de modelo común mediante la fusión de elementos epicúreos y estoicos, aplicable también a algunos modernos como Rabelais, Ronsard, Hobbes, Bayle e incluso Ninon de Lenclos.

No faltan algunos textos literarios (o de literatos) que corroboren estas ideas. Así Voltaire, en el breve diálogo titulado Sophronime et Adélos (1766). Tras una alusión a las Tusculanas de Cicerón, «en las que este gran hombre da prueba con tanta elocuencia que la muerte no es ningún mal», se barajan diversas ideas, sacadas de Catón, Marco Aurelio o Epicteto, para desterrar el miedo a la muerte: que el castigo o la recompensa se conceden en este mundo, y que hay que encararse a la muerte con el sentimiento de haber cumplido con su deber, con la satisfacción de sentirse querido por la gente de bien. Y el diálogo se cierra con una invocación de Epicteto en el momento de su muerte. Poco antes, el propio Voltaire había dado otro diálogo (Dernières paroles d'Epictète à son fils, 1765), en el que, a partir de la idea de la muerte ( «Je vais mourir; j’attends de vous un souvenir tendre, et non des larmes inutiles; je meurs content, puisque je vous laisse vertueux»), se pasa a una sátira de los sacerdotes y de la Iglesia, de la actitud del clero en el momento de la muerte.

Otro ejemplo literario, en la pluma de un filósofo, es la descripción de la muerte de Julie en La nouvelle Hélö̈se de Rousseau. No se trata de una filósofa, deísta o atea, sino de una cristiana que pretende morir en la sencillez y la paz del espíritu:

Jamais elle ne fut plus tendre, plus vraie [...] en un mot plus elle-même. [...] Point de prétention, point d'apprêt, point de sentence, partout la naïve expression de ce qu'elle sentait; partout la simplicité de son cœur. Si quelquefois elle contraignait les plaintes que la souffrance aurait dû lui arracher, ce n'était point pour 
jouer l'intrépidité stoïque, c'était de peur de navrer ceux qui étaient autour d'elle; et quand les horreurs de la mort faisaient quelques instants pâtir la nature, elle ne cachait point ses frayeurs, elle se laissait consoler ${ }^{11}$.

Aun cuando no haya que considerar la muerte de Julie como una muerte «filosófica», Rousseau no pierde la ocasión de poner de manifiesto los terrores que infunde la religión católica. La imagen del catolicismo se proyecta como contrapunto a la religión de Julie, «una religión razonable y santa, que, lejos de embrutecer al hombre, lo ennoblece y lo eleva». Por ello condena las mortificaciones inhumanas y se muestra tiernamente ocupada de los suyos incluso en el momento de su muerte, oponiéndose a tantos consejos sobre el necesario desapego de las cosas de este mundo. Por ello no acumula vanas y secas plegarias, por ello condena el arrepentimiento imperfecto, tardío y forzado dictado por el miedo; implícitamente rechaza la tesis tradicional que concede a los últimos momentos un valor capital, y declara que, dispuesta a comparecer ante el supremo Juez, le presenta toda su vida.

Todo esto respira una sabiduría extrema, una tranquilidad de espíritu que son los que Rousseau desea para sí mismo, y que va a hallar veinte años más tarde, cuando fallece en casa de su protector y amigo el marqués Girardin en su finca de Ermenonville. A diferencia de la muerte de Voltaire, la de Rousseau será tranquila, retirada, en contacto con la naturaleza. Y, según sus deseos, será enterrado en la isla de los Álamos, pequeña isla artificial en el estanque del parque de Ermenonville, donde todavía existe su cenotafio.

Se evitaba así el lamentable espectáculo que pocas semanas antes habían dado en París Voltaire y sus parientes, con el problema del entierro en lugar sagrado. Pero, por lo menos, Voltaire había querido siempre evitar lo contrario. Otros no pudieron realizar sus deseos: así, d'Alembert y Diderot, que por instigación de sus familiares, que no querían que cayera sobre ellos el descrédito social, recibieron sepultura en sagrado, cuando no habían expresado nunca tal deseo. La Iglesia, en este tema, también tenía su monopolio, pudiendo decidir quién tenía derecho o no a un entierro digno, el único posible por otra parte, a un entierro en lugar sagrado, ya fuera en el interior de las iglesias o en los cementerios anejos, y a unas honras fúnebres que debían ser necesariamente religiosas.

\footnotetext{
${ }^{11}$ «Nunca fue más tierna, más verdadera [...], en una palabra, más ella misma. [...] Ni pretensiones, ni afectación, ni sentencias, siempre la ingenua expresión de lo que sentía, siempre la sencillez de su corazón. Si a veces contenía los lamentos que el sufrimiento hubiera debido arrancarle, no era en absoluto para hacer gala de estoica intrepidez, sino por miedo a disgustar a los que la rodeaban; y cuando los horrores de la muerte hacían sufrir a la naturaleza, no ocultaba sus temores y se dejaba consolar.» (J.-J. Rousseau, Julie ou la Nouvelle Héloüse en Euvres complètes, París, Gallimard, 1959-1969, II, pág. 730; la traducción es mía).
} 
Se trataba, en definitiva, de un ejemplo más del poder de la religión cristiana sobre el individuo: el último y el más decisivo, puesto que consistía en extender una especie de salvoconducto para el más allá.

Lo que la filosofía pretendió fue liberar al hombre de ese poder, de esos miedos que coartaban su autonomía y su libertad. 